examination some brown discharge was found in the vagina. The cervix was normal, but the body of the uterus was found to be distinctly enlarged, and the sound passed $3 \frac{3}{8}$ inches. I advised her to have the cervix dilated, so that the endometrium might be explored; this was accordingly done shortly afterwards in a nursing home. For the dilatation, tents were inserted, and the dilatation was completed under anæsthesia next day with Hegar's dilators. On passing the finger into the uterine cavity a polypus of the size of a large walnut was found. It was of firm consistence, and its attachment to the uterine wall was quite definite and circum. scribed. I removed the polypus in the usual way and sent a portion of it for examination to the Laboratories of Public Health. The report on it was as follows: "This tissue has the structure of a very adenomatous polypus. Some of the glands are cystic, the stroma is infiltrated with inflammatory products, but the tissue is benign." The fact that the polypus was non-malignant was the more important as the patient had a feeble, dilated heart, and Dr. F. W. Hewitt, who gave the anæsthetic, considered she would not have stood a major operation such as abdominal hysterectomy.

CASE 2. - This patient was a woman, aged 70 years, who had been married 45 years, and had had three children, the last 35 years previously, and four miscarriages all before the first child. The menopause occurred at the age of 50 years. She came to see me in December, 1908, and said she had been losing blood almost constantly, but not in large amount, for at least 18 months. When she was not bleeding there was a "sticky" vaginal discharge. She had had some back. ache, but no severe pain. On examination the os uteri was a little patulous, but the cervix was otherwise normal. The uterus was not well felt bimanually, as the patient was exceedingly stout. The sound, however, passed $2 \frac{3}{4}$ inches, causing slight bleeding. This patient was admitted shortly afterwards into the London Hospital under my care. The cervix was dilated in the same way as in the preceding case, and a polypus almost exactly similar in size and in microscopic structure was found and removed.

I may add that in July, 1907, I showed a specimen at the Obstetrical Society of a fibroid polypus removed from a patient, 72 years of age. In this case the polypus projected into the vagina through the dilated os uteri. It was the occurrence of bleeding which led to an examination and the discovery of the polypus. Microscopical examination showed that the polypus was not malignant. These three cases are, I think, instructive in showing that even at such advanced ages as 70,72, and 73, the tissues of the uterus may in very rare instances depart from the state of quiescence which then so generally characterises them, and take on an activity leading to the production of benign tumours similar to those so frequently found in adult life before the occurrence of the menopause. Such cases are, however, in my experience very rare; and it should be remembered that, as bleeding after the menopause is so very generally due to the presence of a malignant growth, the benign character of any growth which may be removed in such circumstances should only be accepted as proved after careful microscopical examination.

Another cause of bleeding after the menopause, not due to malignant disease, of some interest is the growth of an ovarian tumour. It is only, however, in rare cases that metrorrhagia is found associated with the growth of an ovarian tumour after the menopause while on the other hand ovarian tumours are common in elderly women. It is not clear why in the majority of such cases there is no metrorrhagia if a causal relation exists between the two conditions. In a certain number, however, it appears that such a relation does exist, since after the removal of the ovarian tumour the metrorrhagia ceases, and does not recur. I recorded some cases of this kind in THF LANCET of Jan. 2nd, 1897, p. 23, and also in THE LANCET of June 16th, 1906, p. 1674.

Upper Brook-street, $W$.

The Medico-Psychological Association.-The spring meeting of the South-Eastern division of the MedicoPsycholngical Association will be held by the courtesy of Dr. E. S. Pasmore at the Crovdon Mental Hospital, Upper Warlingham, on Tuesday, April 27th. Dr. Pasmore kindly invites the members to luncheon to 130 P.M. Dr. Thomas Claye Shaw will read a paper upon the Clinical Value of Consciousness in Insanity.

\section{AN ENORMOUS FACAL TUMOUR IN A GIRL WITH CONGENITAL ABNOR- MALITIES OF HER PELVIC VISCERA.}

By H. B. BUTLER, F.R.C.S. EDIN., ASSISTANT MEDICAL OFFICER TO THE ROYAL SURREY COUYTY HOSPITAL, GUILDFORD:

ARTHUR F. HERTZ, M.A., M.D. OxON., M. R.C.P. LOND.,

ASSISTANT PHYSICIAN TO GUY'S HOSPITAL; AND

W. ARBUTHNOT LANE, M.S. LOND., F.R.C.S. ENG., SURGEON TO GUY'S HOSPITAL.

A GIRL, now aged 16 years, was in St. Thomas's Hospital as an infant because of a congenital abnormality of her rectum. Nothing was done at the time, but her mother was advised to bring her to the hospital when she was a few years old for operative treatment. As the child's general health remained very good this was not done. Her first stool was passed three days after birth, and she became gradually more and more constipated, until, at the age of eight, a month or six weeks frequently elapsed before she opened her bowels. Sometimes after an unusually long period of constipation, fluid fæces would run away from her constantly for about a week. She had also occasional attacks of pain, but her appetite was always good, her tongue clean, and her colour good. She was well developed and was accustomed to take plenty of exercise in the open air. Medical advice was never sought for her until Dec. 15th, 1907, when she was admitted into the Royal Surrey County Hospital, Guildford, under the care of Mr. H. B. Butler. Her temperature was $102^{\circ} \mathrm{F}$. and her pulse was 120 . Her tongue was furred and she looked ill. She complained of severe abdominal pain. The abdomen moved well on respiration, but it was very tender, especially over the right side. A hard, non-fluctuating tumour, dull on percussion, was found coming up from the pelvis ; it resembled in size and position a nterus at the sixth month of pregnancy. On examination under an anæsthetic it was discovered that the patient had no anal canal, her rectum and vagina ending in a common cloaca. The rectum was found to be full of fæces and it appeared probable that the whole tumour was fæcal. A quantity sufficient to fill three large kidney dishes was removed by a blunt spoon; the fæces contained several plum-stones. The tumour did not completely disappear, so aperients and enemata were given during the next three days, with the result that considerable quantities of fæces were evacuated. The temperature steadily fell and was normal on Dec. 18th. The tenderness had completely disappeared, but a tumour of the size of a cricket-ball was still present in the right iliac fossa. The temperature rose on the evening of the 18th and fluctuated between $99^{\circ}$ and $101^{\circ}$ until the 26th, when the patient was again anæsthetised and an incision was made over the mass. Coils of intestine were found adherent to each other and to the parietal peritoneum. A second more lateral incision was made, but the patient's condition did not warrant the long dissection which would have been necessary to penetrate between the intestinal loops in order to reach the tumour, so the first incision was closed and the second was packed with gauze. The prrexia and pain now disappeared, and on Feb. Znd the patient left the hospital apparently well, the wounds having healed and the tumour having disappeared.

On May 16th Mr. Butler was again called to see the patient, whose temperature was $102^{\circ}$. A painful swelling was found in the right iliac fossa. She was readmitted into the Royal Surrey County Hospital and an incision was made over the mass, which was found to be an intraperitoneal abscess. This was evacuated and the wound soon closed and the temperature fell to normal. On August 8th the abdominal tumour had reappeared, the bowels not having been opened since Mar 16th. She was sent to Guy's Hospital, where she was admitted under the care of Dr. A. F. Hertz. She looked the picture of health, was well nourished, with a good colour, healthy skin, moist clean tongue, and gond teeth. Her appetite was excellent. The lower part of the abdomen was completely filled with a very hard tumour, well-defined above and laterally, rising out of the pelvis to a distance of seren 
inches above the pubes, its transverse diameter being eight inches. It was not fixed to the abdominal wall and could be displaced by manipulation as much as the crowded condition of the pelvis allowed. It was dull on percussion and could be pitted by prolonged pressure with the finger, the depression remaining for some time. The urine contained no albumin, pus or casts, and the circulatory, respiratory and nervous systems were quite normal. By means of a bismuth meal it was found that the cæcum, ascending colon, transverse colon and descending colon were normal in size and position, except that the transverse colon was pushed upwards by the tumour. The rate with which the bismuth traversed the colon was also normal. The shadow ended about one and a half inches below the left iliac crest, where the iliac colon apparently joined the enormously distended pelvic colon and rectum, which together formed the sac filled

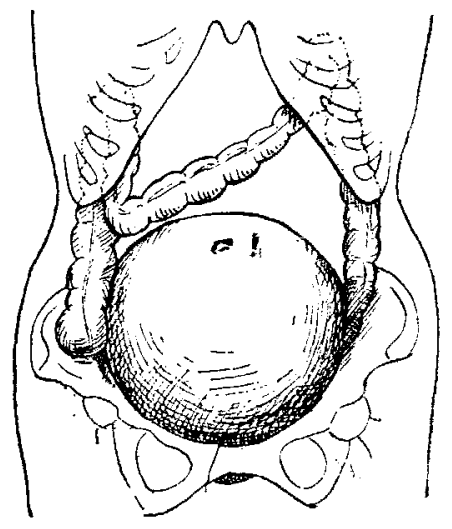

with fæces. The accompanying illustration shows somewhat diagrammatically the relation of the sac containing the faces with the rest of the colon, as ascertained by the skiagraphic examination

On August 12th the patient was anæsthetised and placed in the lithotomy position. By means of two fingers inserted into the rectum and pressure exerted from outside on the tumour the fæcal mass was slowly dug away; subsequently a tube was introduced into the rectum and the irrigation, combined with the use of the finger, enabled the whole accumulation to be removed. The colon was then irrigated until, two hours after the manipulations had begun, the water came away perfectly clear. By weighing the patient before and after the operation it was found that five pounds of fæces had been removed. The fæcal tumour having now been removed, it was possible to investigate more accurately the nature of the congenital abnormality. There was no trace of an anus, anal canal, or sphincter, the rectum opening into the posterior part of a cloaca. The opening had at first admitted one finger only, but it had been stretched until two fingers could be introduced into the rectum. The latter was separated by a transrerse fibrous septum from two vaginæ, which were separated from each other by a median septum, which joined the transverse septum posteriorly. A cervix was found in both vaginæ, but only one uterus could be felt; the greater part of the latter was on the right of the middle line. Probably the septum between the vaginæ was continued into the uterus, the condition being that of " uterus bilocularis." The patient was ordered abdominal massage and faradism and was put on a full diet and allowed to get up. She was given strychnine and cascara sagrada. Whenever her bowels were not opened for 48 hours she was given an enema of cold water. The patient unfortunately insisted on leaving the hospital within a week of the removal of the fæcal accumulation, so that there was no time to ascertain whether the treatment would be effective. Although her mother was instructed to give her enemata regularly she failed to do so. It was, therefore, not surprising that the fæces began to reaccumulate in the rectal sac. When seen on Oct. 24th a large fæcal tumour was again present in the abdomen, somewhat smaller than on the last occasion, and situated more in the left than in the right half of the lower part of the abdomen. In spite of the retention of fæces the patient looked and felt exceedingly well, and was able to walk 12 miles without fatigue. She was, however, much troubled by the continuous escape of small quantities of fluid fæces, apart from which she was unable to produce any evacuation.

The patient was readmitted into Guy's Hospital under the care of Mr. Arbuthnot Lane on Oct. 30th. On Nor. 2nd the fæcal accumulation was again removed under an anæsthetic by the finger with the aid of continuous irrigation, the process lasting two hours. The next day Mr. Lane operated by an incision through the left rectus. The largely dilated and hypertrophied gut was exposed and divided about four inches from its lower extremity, the distal portion being closed and dropped into the pelvis. The proximal portion was pulled out of the wound till the residual bowel was taut. It was then sewn in position, means being taken to constrict the orifice sufficiently. At the operation the lower end of the large intestine was found to have contracted to a considerable extent. It was completely free from all adhesions and the mucous membrane of the excised portion was subsequently found to be quite normal. Adhesions were seen in the right iliac fossa; it appears probable that the abscess previously opened in this situation was appendicular in origin and quite independent of the fæcal tumour. The abdominal examination showed that only a single, apparently normal, uterus was present. The patient made an uninterrupted recovery and was discharged on Nov. 27th. At the end of March, 1909, she was perfectly well and very pleased with the result of the operation.

Apart from the remarkable size of the fæcal tumour and the interesting developmental abnormalities, the case is noteworthy as showing how in some cases prolonged retention of large quantities of frces may occur without producing any anatomical or functional changes. Thus there were no adhesions round the distended intestine; the musculature had not suffered greatly in spite of the long period during which it had been greatly stretched, as the gut was found at the operation to be contracted down almost to the normal size; and the mucous membrane was found to be perfectly healthy on both naked-eye and microscopical examination. Lastly, the patient at no period showed the smallest signs of antointoxication, her complexion being excellent, her nutrition good, and her mental and bodily activity quite normal.

\section{DELAYED DELIVERY IN A CASE OF CENTRAL PLACENTA PREVIA,}

WITH REMARKS ON THE TREATMENT OF THE LATTER.

By N. I. SPRIGGS, M.D., B.S. LOND., F.R.C.S. ENG., IATE HOUSE SURGEON AND OBSTETRIC RESIDENT, GUY'S HOSPITAL.

ON April 17th, 1907, I was called to a woman who was in labour and had been flooding freely. She was a multipara, aged 40 years, and had had 13 full-time confinements and one abortion at three months. In her first labour instruments were used and the perineum was badly ruptured. She said she had "carried all her children high" and the labours were "long and dry." When seen the patient had evidently bled very freely, though the exact quantity of blood lost could not be ascertained. She was blanched and the radial pulse could only just be distinguished. She considered that she was eight months pregnant. On examination the placenta was felt presenting through an os about the size of a five-shilling piece. It could not be determined in which direction the nearest edge of the placenta lay. There were no pains. A saline rectal injection was given, the patient directed to drink freely, and one drachm of liquid extract of ergot administered, as there seemed to be no possibility of any obstruction, and the labour was rather premature. A few hours later the pulse was considerably better, in spite of the fact that the patient had been vomiting. The whole hand was then inserted into the vagina (which was more easily performed than usual on account of the old rupture of the perineum) and the full length of two fingers inserted through the os, but still, on sweeping round the entire circumference of the latter, no indication of the edge of the placenta could be found.

Three courses were now open: (1) to put the whole hand through the os uteri, and so reach the edge of the placenta for the purpose of turning; (2) to try to deliver the placenta first (after Sir James Simpson); this would also need a hand through the os uteri; and (3) to perforate the placenta. The latter procedure was adopted as being the most suitable, as the patient was not under an anæsthetic, neither was she in a 